\title{
Variable Displacement Control of the Concrete Pumping System Based on Dynamic Programming
}

\author{
Min $Y e^{1, a}, \operatorname{Limin}_{\text {Qin }}{ }^{1}$ \\ ${ }^{1}$ National Engineering Laboratory for Highway Maintenance Equipment, Chang'an University, Shaanxi Xi'an, China
}

\begin{abstract}
To solve the problems of cylinder piston striking cylinder and the hydraulic shocking of the main pump, and causing energy waste problem, the method of variable displacement control of piston stroke was proposed. In order to achieve effective control of the piston stroke, variable displacement control model was established under the physical constraint condition of non-collision between piston and cylinder. And the control process was realized by Dynamic Programming(DP), the simulation and test results show that piston of concrete pumping system don't strike cylinder and reduce the hydraulic shock of the main pump outlet, meanwhile improve the response speed of the cylinder and achieve energy-saving purposes under varying loads. This control model built in the integration design space of structure variable and control variable is of guiding significance for solving open-loop system's engineering problems.
\end{abstract}

\section{Introduction}

Concrete pump is widely used in high buildings, highways and other construction projects. It can not only speed up the construction schedule and reduce labor intensity, but also can improve economic efficiency significantly. Since the concrete pump hydraulic systems often work under high pressure condition, and the two main cylinders work alternately, so there will be piston striking and shaking between the changing and increase energy consumption [1-3]. Therefore, it is necessary to research the dynamic characteristics of concrete pump hydraulic system, and find ways to solve reducing the hydraulic shaking. There will be important engineering value to solve the concrete problems.

To solve the foresaid problems engineering and technical personnel have made great efforts. Reference [4] suggests that accumulator or unloading valve should be installed to change structure of valve spool, etc; but without considering variation of the load, this problem cannot be solved completely. Reference [5] proposed that the reason of striking caused by changing was the mismatch oil flow between provided by main pump and the demand of it, and proposed that the main pump and the reversing should be commended synthetically, but no specific control method was given.

This paper discussed the principle of pumping displacement control, and proposed the method of variable displacement control. Based on discussing pump open-loop characteristics, variable displacement piston stroke control model was established on varying load conditions. The position of changing signal point, variable signal point and the value of each variable displacement control period will be determined by Dynamic Programming arithmetic. Finally, concrete pump for pumping process is simulated and analyzed by a model concrete pump and achieve energy saving purposes.

${ }^{\mathrm{a} C}$ Corresponding author : mingye@chd.edu.cn 


\section{Concrete pump working principle and open-loop control characteristics}

Concrete pumping hydraulic system is an open-loop, consists of hydraulic pump, reversing valve, hydraulic cylinder, water tanks and delivery tanks and other components, as shown in the Figure 1. The cylinder piston is connected with concrete delivery cylinder piston by a rigid axle and the reversing valve is electro-hydraulic valve [6]. Sensor sends a changing signal to reversing valve when No. 2 cylinder piston move into the changing control signal point $a$. After some delay time, reversing valve will be triggered to change. No.1 cylinder piston rod will become retracted from extending, and No.2 cylinder rod is retracted into the extended and vice versa. Therefore cylinder to achieve changing, the corresponding delivery cylinder complete feed and suction state switch.

The pump is constant power variable pump, the $p-Q$ characteristic curve shown as Figure 2[7].

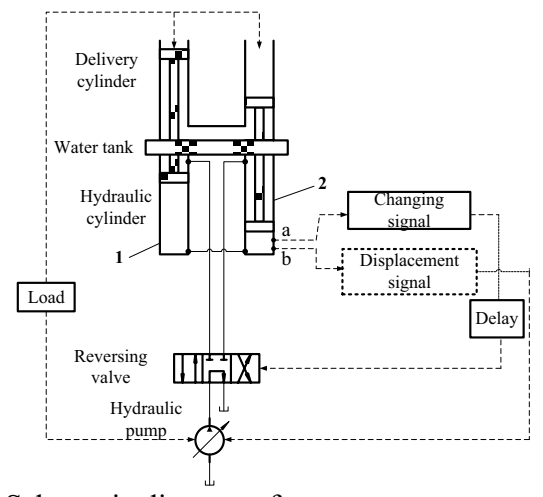

Figure 1. Schematic diagram of concrete pump

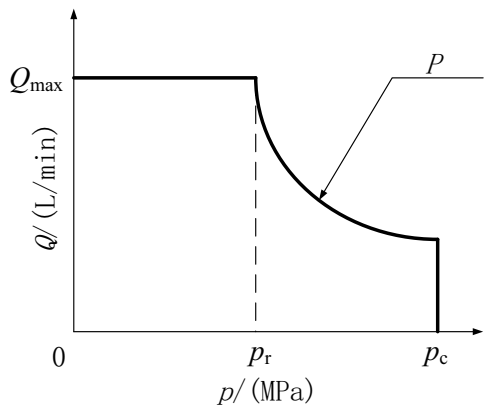

Figure 2. Constant power curve of main pump

As Pascal Theorem known that hydraulic pump outlet pressure is determined by the pumping load. Therefore, we can get the function of relationship between its cylinder piston velocity and the pumping load as follows:

$$
v=\left\{\begin{array}{cc}
\frac{n \cdot V_{g \max }}{60 A_{s}} & \left(0 \leq p_{p}<p_{r}\right) \\
\frac{1000 P}{p_{p} \cdot A_{s}} & \left(p_{r} \leq p_{p}<p_{c}\right) \\
0 & \left(p_{p} \geq p_{c}\right)
\end{array}\right.
$$

Wherein, $v$ is velocity $(\mathrm{m} / \mathrm{s})$ of the piston; $n$ is rated $\operatorname{speed}(\mathrm{r} / \mathrm{min})$ of the pump; $V_{g} \max$ is the maximum displacement of the $\operatorname{pump}(\mathrm{mL} / \mathrm{r}) ; A_{s}$ is piston rod chamber area $\left(\mathrm{mm}^{2}\right)$ of hydraulic cylinder; $P$ is rated power $(\mathrm{kW})$ of the pump; $p_{p}$ is outlet pressure $(\mathrm{MPa})$ of the pump; $p_{r}$ is the pressure(MPa) of the pump when it start control constant; $p_{c}$ is deadline pressure $(\mathrm{MPa})$ of the pump.

By Eq.1, we know hydraulic cylinder piston stroke depends on pumping load ultimately. At present, the commonly used formula to calculate the pumping load as:

$$
p_{L}=\left\{\frac{2}{r}\left[(3-0.1 S) \times 10^{2}+(4-0.1 S) \times 10^{2} \cdot\left(1+\frac{t_{2}}{t_{1}}\right) \bar{v}\right]+\rho g \sin \varphi\right\} x
$$

\section{The variable displacement control model of concrete pump piston stroke}

\subsection{Principle of Variable Displacement Control.}


The basic idea of variable displacement control method of the cylinder piston stroke is to control the main hydraulic cylinder piston stroke by changing the pump displacement. First, the variable displacement signal point was added to the cylinder. Then pump variable displacement control model was built under some constraints. Finally, the position of variable displacement signal point and the each time value of variable displacement control stage were determined by DP arithmetic. The structure parameters of the cylinder are shown in Figure 3. Point $a$ is the location of the reversing valve sensor, and the location is fixed; $b$ is the variable displacement signal point, and different loads with different $b ; c$ is the point at which piston velocity is zero, and different loads with different $c$; $d$ is the bottom of the hydraulic cylinder; $X$ is the location where piston is after the changing signal point; $Y$ is the distance between displacement signal point and point at which piston velocity is zero.

When the cylinder piston motion to point $a$, the sensor sends a signal to the reversing valve. After a certain delay the valve completed reversing. The cylinder piston is still at greater speed during this time, and it will hit bottom before completed changing causing the pump outlet hydraulic shock. Thus, not only the reversing valve should be controlled, but also the cylinder piston speed in the process should be controlled. So point $b$ at which displacement of the variable pump was added to control the speed of cylinder piston. When the cylinder piston move to point $a$ and send out signal to changing, the speed remains unchanged. When the cylinder move to point $b$, the displacement of the variable pump is start to be adjusted. In order to avoid hitting the cylinder under all load condition, there is a certain distance between the piston reaching maximum stroke and the cylinder endpoint bottom, set $e$.

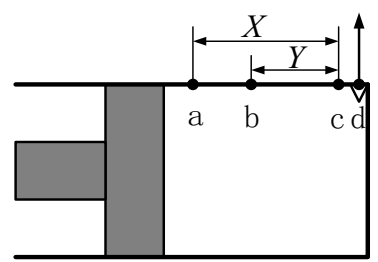

Figure 3. Position of signals on main cylinder

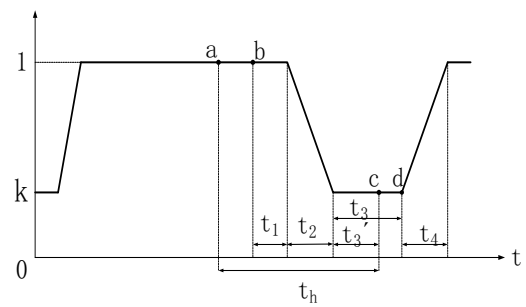

Figure 4. Parameters of changing displacement control

\subsection{Model of Variable Displacement Control.}

As shown in Figure 3, it is parameters of variable displacement control model. The time is set 0 when piston is at point $b$. According to Figure 3 and Figure 4, we could get the distance of piston's moving $s$ from starting variable displacement signal to completing piston's moving. The distance $s$ is:

$$
s=\int_{0}^{t_{1}} v d t+\int_{t_{1}}^{t_{1}+t_{2}}\left[1-\frac{(1-k)\left(t-t_{1}\right)}{t_{2}}\right] v d t+\int_{t_{1}+t_{2}}^{t_{1}+t_{2}+t_{3}^{\prime}} k v d t=v\left(t_{1}+\frac{1+k}{2} t_{2}+k t_{3}^{\prime}\right)
$$

Where: $t_{1}$ is the time between sending variable displacement signal and pump displacement being adjusted; $t_{2}$ is the time between the beginning of the working of displacement control signal and the stable displacement period; $t_{3}^{\prime}$ is the time between the stable displacement and beginning of reverse direction; $k$ is the parameters of displacement control, and in engineering, $k=0.25$.

As shown in Figure4, the time $t_{h}$ between sending changing signal and completing changing is [8]:

$$
\frac{X-Y}{v}+t_{1}+t_{2}+t_{3}^{\prime}=t_{h}
$$

By Eq.3 and Eq.4 we reach:

$$
s=v \cdot\left[t_{1}+\frac{1+k}{2} t_{2}+k \cdot\left(t_{h}-\frac{X-Y}{v}-t_{1}-t_{2}\right)\right]
$$

Putting $v_{\max }, v_{\min }$ into Eq.5 we reach:

$$
s_{\max }-s_{\min }=\left(v_{\max }-v_{\min }\right) \cdot\left[t_{1}+\frac{1}{2}(1+k) t_{2}+k \cdot\left(t_{h}-t_{1}-t_{2}\right)\right]
$$

According to the pumping requirement, the piston stroke must be controlled within a certain range 
under different load conditions. So the difference value between the maximum of the piston stroke and minimum of the piston stroke must be an upper limit value, setting $a$. Then:

$$
s_{\max }-s_{\min }=\left(v_{\max }-v_{\min }\right) \cdot\left[t_{1}+\frac{1}{2}(1+k) t_{2}+k \cdot\left(t_{h}-t_{1}-t_{2}\right)\right] \leq a
$$

In order to reduce the hydraulic pump outlet hydraulic shock changing, the hydraulic cylinder changing must be finished before the hydraulic pump displacement control completed. Namely the hydraulic cylinder changing must be completed in within the time $t_{h}$ period, so $t_{h}$ must satisfy the following relationship:

$$
\frac{X-Y}{v_{\min }}+t_{1}+t_{2}<t_{h}<\frac{X-Y}{v_{\max }}+t_{1}+t_{2}+t_{3}
$$

Where: $t_{3}$ is continuous working time after the value of the pump displacement is the minimum.

In order to avoid hitting the cylinder under all load condition, then $Y \geq s_{\max }$. And in order to make effective stroke of the piston to be maximum, then:

Combine with Eq.3, Eq.8, Eq.9, we reach:

$$
Y=S_{\max }
$$

$$
\frac{X-v_{\text {max }}\left(t_{1}+\frac{1+k}{2} t_{2}+k t_{3}^{\prime}\right)}{v_{\text {min }}}+t_{1}+t_{2}<t_{h}<\frac{X-v_{\text {max }}\left(t_{1}+\frac{1+k}{2} t_{2}+k t_{3}^{\prime}\right)}{v_{\max }}+t_{1}+t_{2}+t_{3}
$$

When pumping load is the maximum, speed of the piston is the minimum and time of the all piston stroke completed is the maximum, we get:

$$
f(t)=\frac{2-v_{\text {max }}\left(t_{1}+\frac{1+k}{2} t_{2}+k \cdot t_{3}^{\prime}\right)-b}{v_{\text {min }}}+t_{1}+t_{2}+t_{3}^{\prime}
$$

In order to improve the pumping efficiency, the time should be the minimum, and the objective function is $\min f(t)$.

\subsection{Dynamic Programming (DP).}

According to the principle of variable displacement pump control, reverse form of Dynamic Programming arithmetic was used to control the adjustment process [9 -11], we get:

$$
f_{k}\left(x_{k}\right)=\underset{u_{k} \in D_{k}\left(x_{k}\right)}{o p t}\left\{v_{k}\left(x_{k}, u_{k}\right)+f_{k+1}\left(x_{k+1}\right)\right\}, k=n, n-1, \ldots, 2,1
$$

Wherein the boundary condition is:

$$
f_{n+1}\left(x_{n+1}\right)=0 \text { or } f_{n}\left(x_{n}\right)=v_{n}\left(x_{n}, u_{n}\right)
$$

Parameter $x_{k}$ is the state of $k$ th stage; decision variable $u_{k}$ is the decision-making in the state $x_{k}$; $x_{k+1}=T_{k}\left(x_{k}, u_{k}\right)$ is state transition equation; $D_{k}\left(x_{k}\right)$ is the set of decision allowable in $k$ th stage; $v_{k}\left(x_{k}, u_{k}\right)$ is index function. In the solution process, optimal decision and optimal value of the process were found at each stage starting from the boundary condition $k=n$. Until $f_{1}\left(x_{1}\right)$ was determined finally, that is the optimal solution of the problem. In the present paper, the position of point $b$ was determined by Dynamic Programming arithmetic meeting the conditions of the piston don't strike cylinder. Notably $b$ is the variable displacement signal point, and different loads with different $b$.

\section{Analysis of the simulation and experimental results}

A concrete pump simulation model was built using MATLAB toolbox Simulink, and the model was shown as Figure 5. 


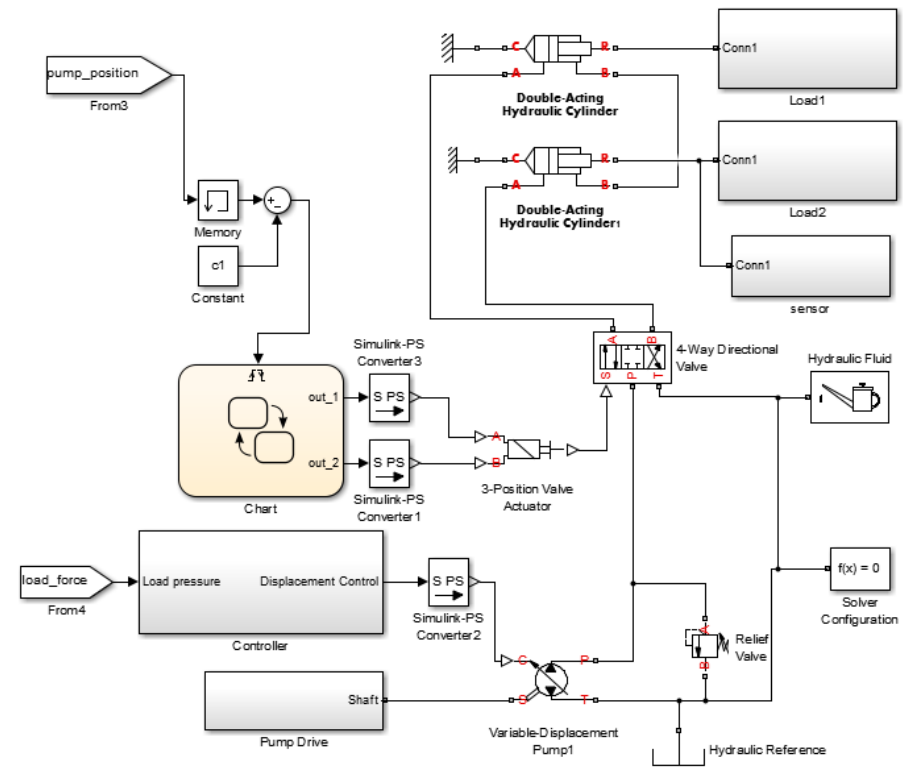

Figure 5. Simulation model of concrete pump pumping

During pumping, the engine and the hydraulic pump are working under power match control.

Wherein the main simulation parameters were shown as Table 1:

Table 1. Main parameters of simulation model

\begin{tabular}{|c|c|c|c|c|c|}
\hline Parameters & Symbol & Value & Parameters & Symbol & Value \\
\hline $\begin{array}{l}\text { Revolving speed of main } \\
\text { pump } /(\mathrm{r} / \mathrm{min})\end{array}$ & $\mathrm{n}$ & 2300 & $\begin{array}{c}\text { Motion Viscosity of } \\
\text { oil } /\left(\mathrm{m}^{2} \cdot \mathrm{s}^{-1}\right)\end{array}$ & $v$ & $3 \times 10^{-5}$ \\
\hline Outer diameter of the & $D_{t}$ & 0.065 & Oil density $/\left(\mathrm{kg} / \mathrm{m}^{-3}\right)$ & $\rho$ & 900 \\
\hline $\begin{array}{l}\text { Inner diameter of the tube } \\
\qquad /(\mathrm{m})\end{array}$ & $d_{t}$ & 0.049 & $\begin{array}{l}\text { Piston diameter of main } \\
\text { cylinder } /(\mathrm{m})\end{array}$ & $\mathrm{D}$ & 0.14 \\
\hline Tube length $/(\mathrm{m})$ & $\mathrm{L}_{\mathrm{t}}$ & 1.5 & $\begin{array}{l}\text { Piston rod diameter of } \\
\text { main cylinder } /(\mathrm{m})\end{array}$ & d & 0.095 \\
\hline $\begin{array}{l}\text { Young's modulus } \\
\text { of tube /(Pa) }\end{array}$ & $\mathrm{E}_{\mathrm{t}}$ & $2 \times 10^{11}$ & $\begin{array}{l}\text { Inertia of piston and } \\
\text { piston rod } /(\mathrm{kg})\end{array}$ & I & 246 \\
\hline Poisson's ratio of tube & $\lambda_{\mathrm{t}}$ & 0.3 & coefficient /(N.m1.s-1) & $\mathrm{R}_{\mathrm{f}}$ & $3.71 \times 10^{4}$ \\
\hline Oil bulk modulus /(Pa) & $\mathrm{E}$ & $1.6 \times 10^{9}$ & $\begin{array}{l}\text { Piston stroke of main } \\
\text { cylinder } /(\mathrm{m})\end{array}$ & $\mathrm{L}$ & 2 \\
\hline
\end{tabular}

A certain type of concrete pump was tested based on the variable displacement control theory, and the main parameters of concrete pump were shown as Table 2.

Table 2. Main parameters of concrete pump

\begin{tabular}{ccc}
\hline Parameters/unit & Symbol & Value \\
\hline Maximum displacement of the main pump $/\left(\mathrm{m}^{3} \cdot \mathrm{s}^{-1}\right)$ & $V_{g \max }$ & $3.167 \times 10^{-6}$ \\
Rated revolving speed of the main pump $/\left(\mathrm{r}^{-1} \mathrm{~s}^{-1}\right)$ & $n$ & 240.855 \\
Rated power of the main pump/W & $P$ & $1.15 \times 10^{5}$ \\
Control pressure of main pump working in constant power $/ \mathrm{W}$ & $p_{r}$ & $1.58 \times 10^{7}$ \\
Outlet pressure of the main pump/(Pa) & $p_{p}$ & $(6 \sim 30) \times 10^{6}$ \\
Rod chamber piston area of the main cylinder/ $\mathrm{m}^{2}$ & $A_{s}$ & $8.31 \times 10^{-3}$ \\
Piston stroke of the main cylinder $/ \mathrm{m}$ & $s_{p}$ & 2 \\
Changing time of hydraulic system $/ \mathrm{s}$ & $t_{h}$ & 0.2 \\
\hline
\end{tabular}

The model of the control system was simulated with DP arithmetic and experimental data also imported in, then we reached the following results. 


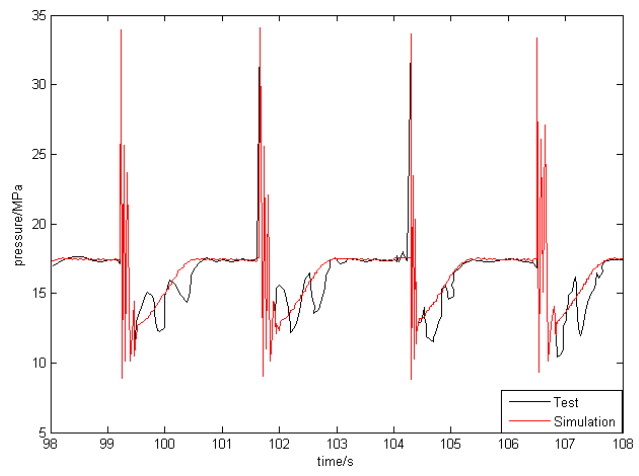

a

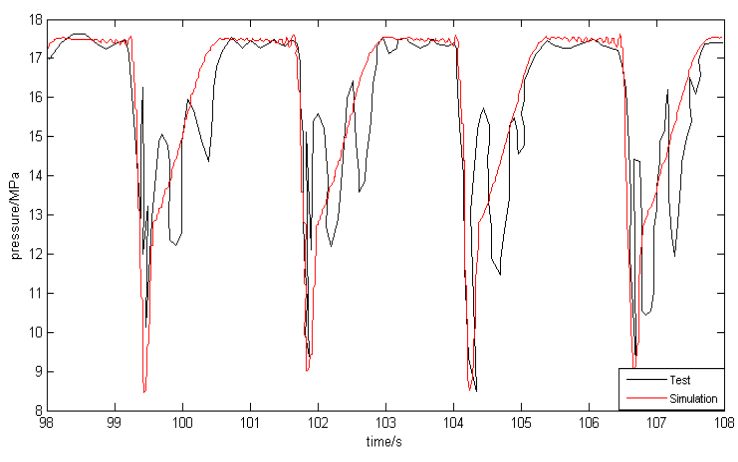

b

Figure 6. Pressure of main pump with changing displacement control

The simulation and the experiment curve of the outlet pressure of hydraulic pump without control are shown individually in Figure 6 a. The pump outlet pressure hold steady after slowly increasing to $17.5 \mathrm{MPa}$, and there has hydraulic shocking when the cylinder changing, peak pressure up to $33 \mathrm{MPa}$ about two times the normal working pressure. The simulation and the experiment curve of the outlet pressure of hydraulic pump with variable displacement control are shown individually in Figure $6 \mathbf{b}$. The outlet pressure of pump is gradually increased and stabilized, and there is no peak value of the outlet pressure after changing. Also there is no crash in test site. It can avoid striking the cylinder and reduce the outlet shocking of the pump by controlling variable displacement of piston stroke. Experiment shows that the fluctuation rang of engine speed are lower under variable displacement control than without control, and the fuel consumption of the engine is much lower.

\section{Conclusion}

To solve the problems of cylinder piston striking and the hydraulic shocking of the pump when the cylinder changing, the method of variable displacement control of piston stroke was proposed. The control model of concrete pump piston stroke was built. The position of variable displacement signal point and the value of each time period were decided by DP arithmetic under different load. And the control process was realized by DP, the simulation and test results show that piston of concrete pumping system don't strike cylinder and reduce shock of the pump outlet, meanwhile improve the response speed of the cylinder and achieve energy-saving purposes under varying loads. Since the variable displacement piston stroke control method is based on the general concrete pump, it has some versatility. There has some reference value for similar problem of automotive pumps or trailer pump.

\section{References}

1. L. F. Jie, L. Liu, Y. Li, Zh. Sh. Cheng. Hydraulics Pneumatics \& Seals 10, 56, (2010).

2. Zh. X. Li, Sh. X. Wang, H. Jiang. Machinery Design \& Manufacture 6, 76, (2011).

3. M. Ye, X. G. Yi, Sh. J. Jiao, Energy Procedia 88,574, (2016).

4. B. X. Cao, G. A. Chen, T. J. Fan. Proceeding of the sixth international conference on fluid power transmission and control (International Academic Publisher, Beijing, 2005).

5. G. A. Chen, T. J. Fan, B. X. Cao, Construction Machinery and Equipment 39, 10, (2008).

6. W. R. Wu, Zh. W. Mao, X. Y. Huang, Computer Simulation 31, 222,(2014).

7. R. K. Guo, J. Li, G. X. Chen. Computer Simulation 32, 239-244, (2015).

8. A. L. Wang, X. H. Yu, B. Shi. Journal of Shanghai Jiaotong University 43, 114, (2009).

9. Miguel Areias, Ricardo Rocha, The Journal of System \& Software 8, 1, (2016).

10. W. F. Lan, Z. Y. Wu, Q. Li, X. Li. Qiang, Journal of South-Central University for Nationalities 35, 135, (2016).

11. J. Chen, Computer and Information Technology 21, 23, (2013). 